Personalidade Acadêmica Homenageada:

Augustus B. Cochran III (Agnes Scott College)

\title{
UM PAI CUIDA DE DEZ FILHOS, MAS DEZ FILHOS NÃO CUIDAM DE UM PAI": CAUSAS E CONSEQUÊNCIAS DO ABANDONO AFETIVO DE IDOSOS NO BRASIL
}

\section{A FATHER CARES FOR TEN CHILDREN, BUT TEN CHILDREN DON'T CARE FOR A FATHER": CAUSES AND CONSEQUENCES OF AFFECTIVE ABANDONMENT OF ELDERLY IN BRAZIL}

TAMARA FACCION RODRIGUES Graduanda em Direito, modalidade integral, pela Escola Superior Dom Helder Câmara. Belo Horizonte. E-mail: tamarafraccioncastro@hotmail.com

CAIO AUGUSTO SOUZA LARA Mestre e Doutor em Direito pela Faculdade de Direito da Universidade Federal de Minas Gerais - UFMG. Professor da Escola Superior Dom Helder Câmara. Pesquisador Associado ao Programa RECAJ-UFMG - Acesso à Justiça e Solução de Conflitos. Secretário de Comunicação do Conselho Nacional de Pesquisa e Pósgraduação em Direito - CONPEDI. Belo Horizonte-MG. E-mail: caiolarabh@yahoo.com.br.

RESUMO

O tema-problema da pesquisa que se pretende desenvolver é o do abandono afetivo no Brasil. Ademais, será abordado perspectivas jurídicas e sociais relacionadas à população idosa brasileira. Indubitavelmente, a sociedade passou por inúmeras transformações durante o século XX, principalmente no âmbito econômico e social, tendo como consequência a priorização do lucro em detrimento da venda da 


\section{Personalidade Acadêmica Homenageada:}

Augustus B. Cochran III (Agnes Scott College)

força física. Assim sendo, os idosos foram colocados em um patamar de carga econômica para suas famílias, visto que devido à idade avançada e diversos fatores biológicos comuns da idade não conseguem trazer recursos econômicos da mesma forma para o núcleo afetivo. De acordo com estimativas do IBGE realizadas em 2017, em 2042 a projeção é de que a população brasileira atinja 232,5 milhões de habitantes, sendo 57 milhões de idosos (24,5\%). Por consequente, com o aumento considerável da expectativa de vida com passar das décadas e, portanto, o aumento da população idosa se viu necessário a ampliação dos direitos dessa população. Um marco importante para a legislação do Brasil foi a Constituição de 1988, conhecida como a Constituição Cidadã, a qual adotou preceitos fundamentais da Declaração Universal dos Direitos Humanos da ONU, de 1949, os quais se aplicam também à população idosa. Outro acontecimento de extrema relevância foi a promulgação em primeiro de outubro de 2003 do Estatuto do Idoso, destinado a regulamentar os direitos assegurados às pessoas com idade igual ou superior a 60 (sessenta) anos que vivem no Brasil. Entretanto, mesmo com seus direitos garantidos juridicamente muitas inflações são recorrentes referente aos idosos. Sendo assim, discussões acerca do abandono afetivo são de extrema importância, tendo em vista que o envelhecimento da população é um acontecimento atual e presente na sociedade brasileira. O problema objeto da investigação científica proposta é: quais são as causas e as consequências jurídicas do abandono afetivo de idosos no Brasil? A partir das reflexões preliminares sobre o tema, é possível afirmar inicialmente que as causas para o abandono afetivo de idosos no Brasil sejam o envelhecimento da população juntamente com uma sociedade cada vez mais individualista e egoísta. Todavia, as consequências dessa adversidade são drásticas. Entre elas estão: problemas psicológicos como a depressão, ansiedade somados com a potencialização de problemas físicos que já são comuns pela idade, bem como as violações de normas de proteção importantes com o Estatuto do Idoso. O objetivo geral do trabalho é analisar os motivos que geram o abandono afetivo de idosos e constatar seus efeitos, assim como examinar a sociedade brasileira atual, para que dessa forma se estabeleça um panorama de qual é a verdadeira situação do idosos no Brasil, tanto no âmbito jurídico como social. A pesquisa que se propõe pertence à vertente 


\section{Personalidade Acadêmica Homenageada:}

\section{Augustus B. Cochran III (Agnes Scott College)}

metodológica jurídico-sociológica. No tocante ao tipo de investigação, o tipo jurídicoprojetivo. O raciocínio desenvolvido na pesquisa será predominantemente dialético. De acordo com a técnica de análise de conteúdo, afirma-se que se trata de uma pesquisa teórica, o que será possível a partir da análise de conteúdo dos textos, doutrinas, normas e demais dados obtidos na pesquisa. A partir do exposto, concluise que cuidar de um idoso não é somente prestar auxílio financeiro. É também necessário garantir a eles dignidade, afeto, carinho e atenção, como em concordância com o Artigo 230, da Constituição Federal, que assim dispõe: "A família, a sociedade e o Estado têm o dever de amparar pessoas idosas, assegurando a sua participação na comunidade, defendendo a sua dignidade e bem-estar e garantindo-lhes o direito à vida".

PALAVRA-CHAVE: Idosos; Abandono Afetivo; Família; Estatuto do Idoso.

\section{REFERÊNCIAS}

AGUIARIO, Aguiario. O idoso como cidadão: Enfrentando o abandono familiar da pessoa idosa. 2016. 57 f. (Serviço Social) - Universidade Federal Fluminense, Rio das Ostras: RJ, 2016.

ARISTON, Ana Paula. Proteção aos idosos. Rio de Janeiro: Juruá, 2007.

BRASIL. Constituição da República Federativa do Brasil de 1988. Disponível em: http://www.planalto.gov.br/ccivil_03/constituicao/constituicao.htm. Acesso em: 30 abr. 2019.

GUSTIN, Miracy Barbosa de Sousa; DIAS, Maria Tereza Fonseca. (Re)pensando a Pesquisa Jurídica. 4. ed. Belo Horizonte: Del Rey, 2015.

KAFER, Giovana. Abandono afetivo de pais idosos: A responsabilidade civil dos filhos. 2018. 74 f. Monografia (Especialização em Direito Civil e da Família) Universidade do Vale do Taquari, Lajeado, RS, 2018.

MENDES, Roberta de. Direitos e garantias do idoso: doutrina, jurisprudência e legislação. 3. ed. São Paulo: Atlas, 2015. E-book. Disponível em: <https://integrada.minhabiblioteca.com.br>. Acesso em: 24 abr. 2019. 
Personalidade Acadêmica Homenageada:

Augustus B. Cochran III (Agnes Scott College)

STURZA, Janaína Machado; GRANDO, Juliana Bedin. Controle social e políticas públicas: um debate fundamental para o amparo de idosos. Revista Jurídica UNICURITIBA, Curitiba, v.1 n.28, $2015 . \quad$ Disponível em: http://revista.unicuritiba.edu.br/index.php/RevJur/article/view/3305/371371798. Acesso em: 21 mai. 2019.

WITKER, Jorge. Como elaborar uma tesis en derecho: pautas metodológicas y técnicas para el estudiante o investigador del derecho. Madrid: Civitas, 1985. 